\title{
Identification and Bioinformatic Analysis of the ASAT Gene Family in Oryza staiva
}

Sun Wenli, Shi Jianxin $\square$

Joint International Research Laboratory of Metabolic \& Developmental Sciences, School of Life Sciences and Biotechnology, Shanghai Jiaotong University, Shanghai, 200240, P.R. China

\ Corresponding author email: jianxin.shi@sjtu.edu.cn

Rice Genomics and Genetics, 2021, Vol.12, No.1 doi: 10.5376/rgg.2021.12.0001

Received: 07 Jun., 2021

Accepted: 12 Jul., 2021

Published: 30 Jul., 2021

Copyright $(1) 2021$ Sun and Shi, This article was first published in Molecular Plant Breeding in Chinese, and here was authorized to translate and publish the paper in English under the terms of Creative Commons Attribution License, which permits unrestricted use, distribution, and reproduction in any medium, provided the original work is properly cited.

Preferred citation for this article:

Sun W.L., and Shi J.X., 2021, Identification and bioinformatic analysis of the ASAT gene family in Oryza staiva, Rice Genomics and Genetics, 12 (1): 1-16 (doi: $\underline{10.5376 / \text { rgg.2021.12.0001) }}$

\begin{abstract}
Rice bran oil is rich in bioactive steryl ferulates that are important not only for seed development, drought stress and lipid metabolism, but also for grain nutrition quality and human healthy. However, its complete compositions and associated metabolic pathways are poorly understood. Arabidopsis thaliana Acyl-CoA Sterol Acyltransferase1 (AtASAT1) is the only one in the superfamily of Membrane-Bound O-Acyltransferases that has ASAT activity, which prefers saturated fatty acyl-CoAs as acyl donors and cycloartenol as the acyl acceptor. Overexpression of AtASAT1 in Arabidopsis results in a strong accumulation of cycloartenol fatty acyl esters accompanied by an increase of the whole steryl esters contents in seeds. Here we present our bioinformatic based analysis data aiming to identify more plant ASAT family members and to in silico study of them in rice. We identified 105 ASAT Family members from public genome database of 10 plant species including Arabidopsis and tomato, and the phylogenetic tree of ASAT family constructed revealed evolutionary relationships of ASAT family members between oil-bearing crop and non-oil-bearing species, and between monocotyledons and dicotyledons. We further investigated into physical and chemical properties of 14 OsASAT proteins, and chromosome distributions, structures and promoter sequences, and expression patterns of corresponding OsASAT genes, providing a solid theoretical basis for further study of the biological functions of OsASAT proteins.
\end{abstract}

Keywords Sterol esterification; ASAT; Protein structure; Molecular evolution; Expression pattern

Rice (Oryza sativa) is the main grain consumed by about 3.5 billion people all over the world. And rice bran is a by-product of rice milling process, which is rich in bioactive chemicals, such as polyphenols, peptides and lipids (such as phytosteryl ferulate), and have the ability to remove free radicals and prevent diseases (Saji et al., 2019). At present, the most studied rice bran oil is steryl ferulate, which is a mixture of sterol and ferulic acid esterification. It is generally believed that rice bran oil mainly exists in the bran, embryo and endosperm of mature rice grains (Hernandez et al., 2016). During rice grain maturation, steryl ferulate is involved in maintaining the integrity and fluidity of plant cell lipid membranes, membrane lipid homeostasis, and regulating membrane permeability, fluidity, signal transduction and membrane binding enzyme activity in cell division (Kumar et al., 2015; Valitova et al., 2016). More and more studies have shown that steryl ferulate have positive health effects, such as lowering cholesterol, antioxidant (Faulds, 2010; Bumrungpert et al., 2019; Lai et al., 2019). Although rice bran oil has a variety of confirmed and expected biological activities, the biosynthesis pathway of steryl ferulate in plants is not clear (Zhu, 2015). From its molecular structure, the biosynthesis of steryl ferulate in plants may begin with the synthesis of sterol and ferulic acid, and then the esterification of ferulic acid and sterol. It has been reported that acyltransferase is involved in the biosynthesis of steryl ferulate (Kumar et al., 2015).

Sterol acyltransferases are a family of enzymes that catalyze the transfer of fatty acil groups to the hydroxyl group at C-3 position of the sterol backbone. Sterol acyltransferases are categorized into acyl-CoA: sterol acyltransferases (ASAT) and phospholipids: sterol acyltransferases (PSAT) depending on whether the fatty acyl donor substrate is a long-chain acyl-CoA or a phospolipid. It is reported that phytosterol acyltransferase activity is mainly related to the membrane components of different species (Banas et al., 2005; Chen et al., 2007; Bouvier-Navé et al., 2010) and has broad-spectrum characteristics of participating in phytosterol metabolism. For 
example, sterol acyltransferase activity increases during seed development in rape and tobacco (Harker et al., 2003). And Arabidopsis AtASAT1 and tomato SIASAT1 not only participate in sterol ester synthesis, but also affect the development of plant organs and tissues. But so far, ASAT enzymes in other plants have not been cloned and identified.

AtASAT1 is the only member with ASAT gene activity in Arabidopsis MBOAT gene family. The protease AtASAT1 encoded by AtASAT1 prefers saturated fatty acyl-CoAs as acyl donors and cycloartenol as the acyl acceptor. Overexpression of AtASAT1 in Arabidopsis results in a strong accumulation of cycloartenol fatty acyl esters accompanied by an increase of the whole steryl esters contents in seeds (Chen et al., 2007; Bouvier-Navé et al., 2010). In addition, the content of steryl esters contents in leaves and seeds of atasat 1 mutant decreased significantly, and it was also proved that AtASAT1 was closely related to the balance of free sterols during leaf senescence in Arabidopsis thaliana (Bouvier-Navé et al., 2010). Tomato genome contains as many as 8 genes that encode ASAT proteins, among which Solycllg012260 gene, or SlASAT1, encodes the largest protein in the family (444 amino acid residues), which is also the gene with the highest homology with AtASAT1 (49\%). SlASAT1 was used to supplement Arabidopsis asat1-1 mutant. And it was found that the enzyme had obvious sterol substrate preference and could significantly increase the synthesis of sterol cycloartenol and 24-methylene cycloartanol (Lara et al., 2018). And tomato SIASAT1 also has dual roles in tomato plant and fruit development and stress response and has obvious substrate preference for phytosterol precursor cycloartenol and 24-methylene cycloartanol (Lara et al., 2018). It is worth noting that AtASAT1 is located in endoplasmic reticulum (ER) and SlASAT1 is located in plasma membrane (PM). These studies show that phytosterol acyltransferases are indeed involved in the esterification of alcohols and acids, but the species and biological functions of sterol acyltransferases in rice have not been elucidated. The molecular evolution characteristics, expression patterns and biological functions of sterol acyltransferases in different species have not been systematically compared.

In order to fully reveal the biological function, expression pattern and protein structure of ASAT family in rice, compare the evolution characteristics of ASAT protein in monocotyledons and dicotyledons, and predict the role of rice ASAT family members in rice steryl ester metabolism and their effects on rice growth, development and stress response, bioinformatics analysis was used in this study. We identified 105 ASAT Family members from public genome database of 10 plant species including Arabidopsis and tomato, and the phylogenetic tree of ASAT family constructed revealed evolutionary relationships of ASAT family members between oil-bearing crop and non-oil-bearing species, and between monocotyledons and dicotyledons. We further investigated into physical and chemical properties of 14 OsASAT proteins, and chromosome distributions, structures and promoter sequences, and expression patterns of corresponding OSASAT genes, providing a solid theoretical basis for further study of the biological functions of OsASAT proteins in the metabolic pathway of rice bran oil.

\section{Results and Analysis}

\subsection{Identification of ASAT family}

AtASAT1 protein sequence was used as query, and the blastp program was used to search the protein data of three food crops rice (Oryza sativa, Japonica Group, asSEsmbly Build 4.0), maize (Zea mays, asSEsmbly B73 RefGen_v4), and sorghum (Sorghum bicolor, asSEsmbly Sorghum_bicolor_NCBIv3), four oil crops rape (Brassica napus, asSEsmbly Bra_napus_v2.0), soybean (Glycine max, asSEsmbly Glycine_max_v2.1), peanut (Arachis hypogaea, asSEsmbly arahy.Tifrunner.gnm1.KYV3), and sesame (Sesamum indicum, asSEsmbly S_indicum_v1.0) and two cash crops tomato (Solanum lycopersicum, asSEsmbly SL3.0), and tobacco (Nicotiana tabacum, asSEsmbly Ntab-TN90), and 128 candidate family members were obtained. After using conserved domain analysis and tblastn to remove redundant sequences, 105 candidate ASAT families were obtained. Among them, 6 rice OsASAT identified were homologous with the reported Arabidopsis AtASAT1, and the 8 tomato SIASAT identified were also consistent with the reported (Lara et al., 2018), which confirmed the reliability of the results. We named 105 ASAT homologous proteins as "species+ASAT+number" (Table 1) according to their position on the chromosome. And 14 candidate OsASAT family members in rice were selected as key analysis objects. 


\subsection{Evolutionary relationship of ASAT protein in different species}

In order to explore the phylogenetic relationship of ASAT family proteins in plants, 105 ASAT proteins from 9 different plant species were identified, and the maximum likelihood method was used to construct the phylogenetic tree of ASAT (Figure 1). It is obvious that the genetic distance between Arabidopsis AtASAT1 and peanut, rape and rice is close, which means this protein may be more similar to peanut, rape and rice in origin and evolution. We also noticed that the OsASAT proteins of rice were distributed in all evolutionary branches, and the genetic distances of OsASAT2, OsASAT2, OsASAT3, OsASAT4, OsASAT5, OsASAT6 and OsASAT9 were close to Arabidopsis AtASAT1. And the genetic distances of OsASAT1, OsASAT7, and OsASAT13 were close to tomato SlASAT1. These results suggest that different OsASAT proteins have different functions, some of which are similar to Arabidopsis homologous proteins, others are similar to tomato homologous proteins. On the other hand, the ASAT proteins of rice, maize and sorghum in food crops showed clustering phenomenon, which indicated that the homology between proteins was good, and the time of evolution divergence was closer. And it is worth noting that in typical oil crops, such as peanut, soybean and rape have relatively close ASAT family proteins, while sesame ASAT proteins are scattered. These results suggest that the ASAT protein family may play a role in the evolution or differentiation of oil and food crops, and also suggest that ASAT protein may have different enzyme activities or functions in different crops. We pay more attention to OsASAT, so the following analysis mainly focuses on OsASAT.

\subsection{Whole genome analysis of OsASAT encoding gene in Rice}

14 OsASAT protein coding genes were identified in rice database by homologous search method, which were unevenly distributed on chromosomes 1, 2, 4 and 7 (Table 2; Figure 2). We noticed that the OsASAT on chromosomes 2 and 4 formed two gene clusters respectively (Figure 2). There is a great difference in the size of OSASAT gene. The longest cDNA is $4599 \mathrm{bp}$, while the shortest cDNA is only $435 \mathrm{bp}$ (Table 2). In addition, the structure of OSASAT gene varies greatly among individuals. Among them, 7 have no introns, while the remaining genes have different numbers of introns (1 9) (Figure 3). The results of selection site analysis (Table 2) showed that the non synonymous sites of the OSASAT gene family were more than the synonymous sites, indicating that they were relatively conservative in the process of evolution, that is, the rice $O S A S A T$ gene family tended to purify selection.

\subsection{Analysis of physical and chemical properties of rice ASAT family proteins}

In order to further clarify the protein structure and properties of ASAT family members in rice, we characterized the basic physical and chemical properties of 14 OsASAT family proteins in rice (Table 3 ). The results showed that the sequence of OsASAT protein ranged from 264 to 403 amino acids, and there were some differences among individuals. The molecular weight of family members is between 28.7 and $43.95 \mathrm{kD}$, which is similar to that of Arabidopsis AtASAT1, but there are also some differences among members. The positively charged residues were more than negatively charged residues, and the theoretical isoelectric points were more than 7 , ranging from 9.48 to 10.92 , indicating that OsASAT family proteins are rich in basic amino acids. The analysis of the above proteins by ProtScale showed that the aliphatic index of OsASAT proteins was more than 80 , ranging from 100.58 to 113.02 , indicating that the OsASAT family proteins had high fat solubility and thermal stability. However, the OsASAT family proteins showed strong hydrophobicity at the same time, and the hydrophobic index was more than 40 . Because the proteins with strong hydrophobic waters are generally unstable, and the proteins with instability index more than 40 are also unstable proteins (Gasteiger et al., 2005), it can be concluded that 14 OsASAT family proteins are unstable proteins in theory. 
Rice Genomics and Genetics 2021, Vol.12, No.1, 1-16

http://cropscipublisher.com/index.php/rgg

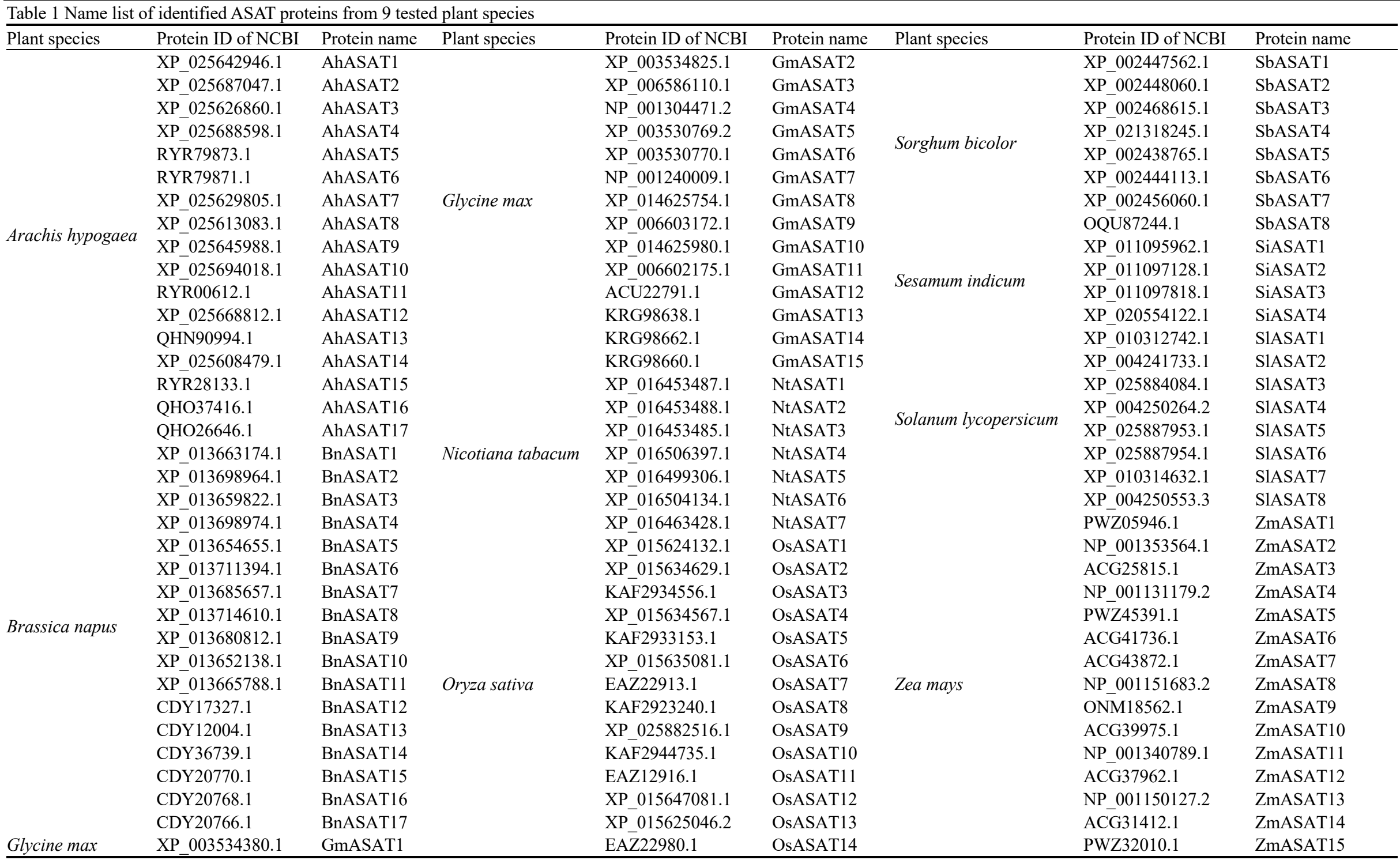




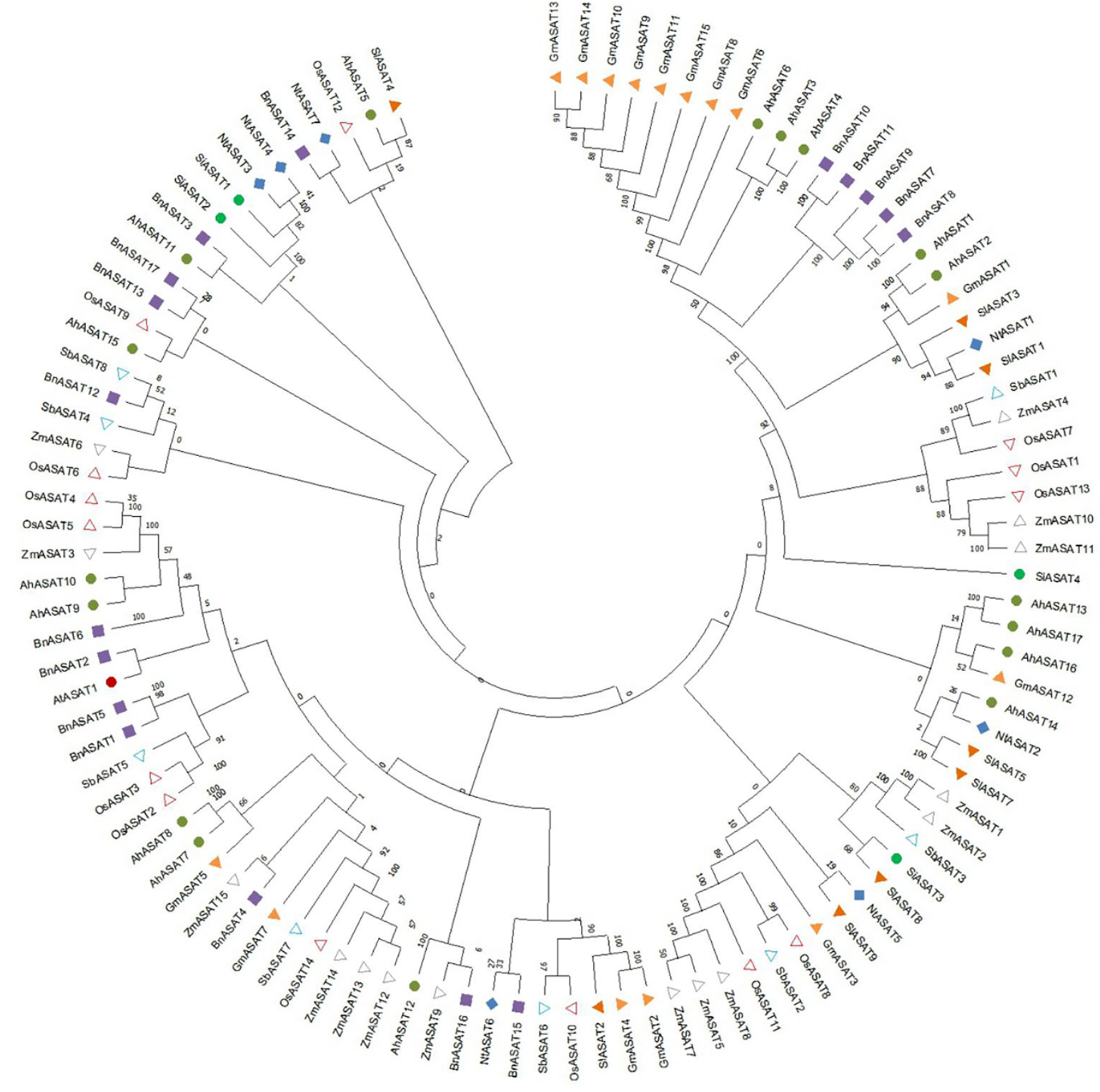

Figure 1 Phylogenetic tree of ASAT proteins

Note: At: Arachis hypogaea; An: Arachis hypogaea; Bn: Brassica napus; Gm: Glycine max; Nt: Nicotiana tabacum; Os: Oryza sativa; Si: Sesamum indicum; S1: Solanum lycopersicum; Sb: Sorghum bicolor; Zm: Zea mays

\subsection{Localization, secondary structure and phosphorylation site analysis of rice ASAT family proteins}

In order to analyze the biochemical properties and molecular functions of OsASAT family proteins, we analyzed the localization, secondary structure and phosphorylation sites of OsASAT family proteins (Table 4). The results of protein subcellular localization prediction showed that OsASAT protein localization is diverse, suggesting that it may have a variety of biological functions. The proportion of OsASAT family proteins located in chloroplast and plasma membrane is the largest, which is similar to that of Arabidopsis and tomato (Chen et al., 2007; Lara et al., 2018). The protein secondary structure showed that there were 2 similar $\alpha$-helix and 7 similar $\beta$-sheet in the secondary structure of OsASAT family members, and all of them had the characteristics of $\alpha$-helix $(49.86 \% \sim 57.8 \%)$ and random coil $(26.69 \% \sim 35.17 \%)$, which may be due to the conservative domain MBOAT_2 $\alpha$-helix (37.41\%) and random coil (42.69\%) accounted for the highest proportion. The results of transmembrane domain analysis showed that there were 5 to 8 transmembrane helical structures in OsASAT protein, which was slightly lower than that in Arabidopsis AtASAT1, which indicated that OsASAT protein was probably located in membrane-related structures, such as plasma membrane, chloroplast membrane or mitochondrial membrane, 
which was consistent with the prediction of subcellular localization of OsASAT protein mentioned above. The analysis of phosphorylation sites showed that there were few phosphorylation sites in OsASAT family proteins, ranging from 15 to 27, and most of them were concentrated in serine. And prediction results of signal peptides showed that no signal peptides were detected in 14 OsASAT family proteins, indicating that these proteins are likely to be non-secretory proteins, which is the same as Arabidopsis AtASAT1.

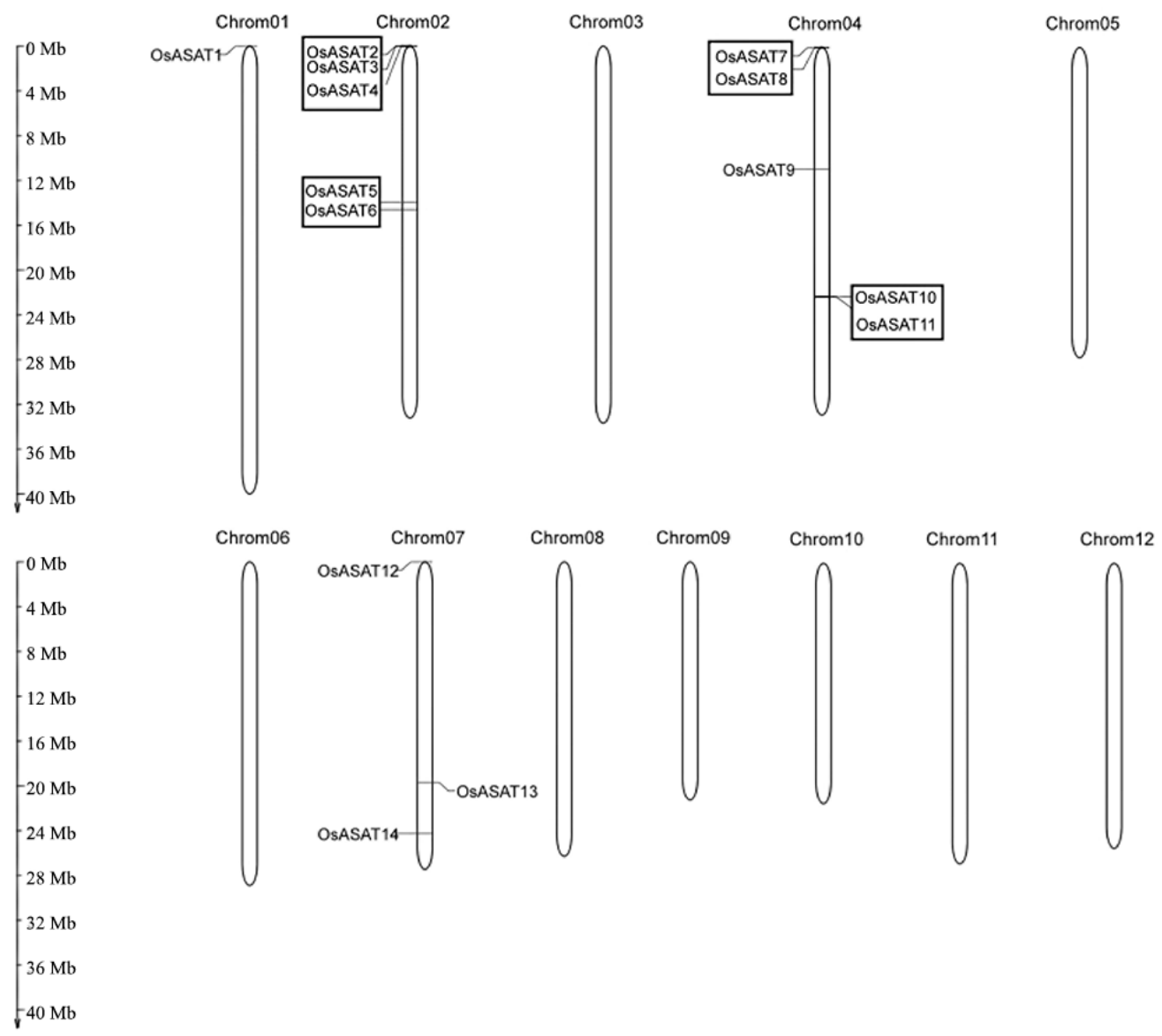

Figure 2 Distribution of $A S A T$ genes on rice chromosomes

Note: The chromosome number is indicated above each bar. Boxes: The gene cluster. The scale on the left is in base pair (bp)

Table 2 Basic information of ASAT encoding gene family members in rice

\begin{tabular}{llllllll}
\hline Gene ID & Gene name & Chrome & Starting point & Ending point & Gene length (bp) & $\begin{array}{l}\text { Synonymous } \\
\text { sites }\end{array}$ & $\begin{array}{l}\text { Non Synonymous } \\
\text { sites }\end{array}$ \\
\hline LOC_Os01g01010.1 & OsASAT1 & Chr1 & 4754 & 5797 & 1044 & 93.5 & 332.5 \\
Os02g0100050 & OsASAT2 & Chr2 & 392 & 2696 & 2305 & 96.83 & 329.17 \\
LOC_Os02g01020.1 & OsASAT3 & Chr2 & 9298 & 13896 & 4599 & 96.33 & 329.67 \\
LOC_Os02g01030.1 & OsASAT4 & Chr2 & 14061 & 18598 & 1125 & 90 & 336 \\
LOC_Os02g25700.1 & OsASAT5 & Chr2 & 15044756 & 15045814 & 1059 & 112.5 & 313.5 \\
LOC_Os02g26840.1 & OsASAT6 & Chr2 & 15759511 & 15760551 & 1041 & 118 & 308 \\
LOC_Os04g01006.1 & OsASAT7 & Chr4 & 2032 & 3679 & 855 & 93.83 & 332.17 \\
LOC_Os04g01008.1 & OsASAT8 & Chr4 & 4951 & 8636 & 2463 & 101.5 & 324.5 \\
LOC_Os04g20880.1 & OsASAT9 & Chr4 & 11720537 & 11721807 & 1035 & 114.83 & 311.17 \\
LOC_Os04g40580.1 & OsASAT10 & Chr4 & 24098305 & 24099665 & 1050 & 121 & 305 \\
LOC_Os04g40590.1 & OsASAT11 & Chr4 & 24101138 & 24102493 & 1038 & 123.5 & 302.5 \\
LOC_Os07g01010.1 & OsASAT12 & Chr7 & 2362 & 3134 & 435 & 96 & 330 \\
LOC_Os07g35570.1 & OsASAT13 & Chr7 & 21293128 & 21294251 & 1124 & 116.5 & 309.5 \\
LOC_Os07g44030.1 & OsASAT14 & Chr7 & 26311992 & 26313267 & 1276 & 104.33 & 321.67 \\
\hline
\end{tabular}

Note: Cyto: Cytoplasm; Chlo: Chloroplast; ER: Endoplasmic reticulum; Mito: Mitochondria; Nucl: Nucleus; Plas: Plasma membrane; Vacu: Vacuole 
Rice Genomics and Genetics 2021, Vol.12, No.1, 1-16
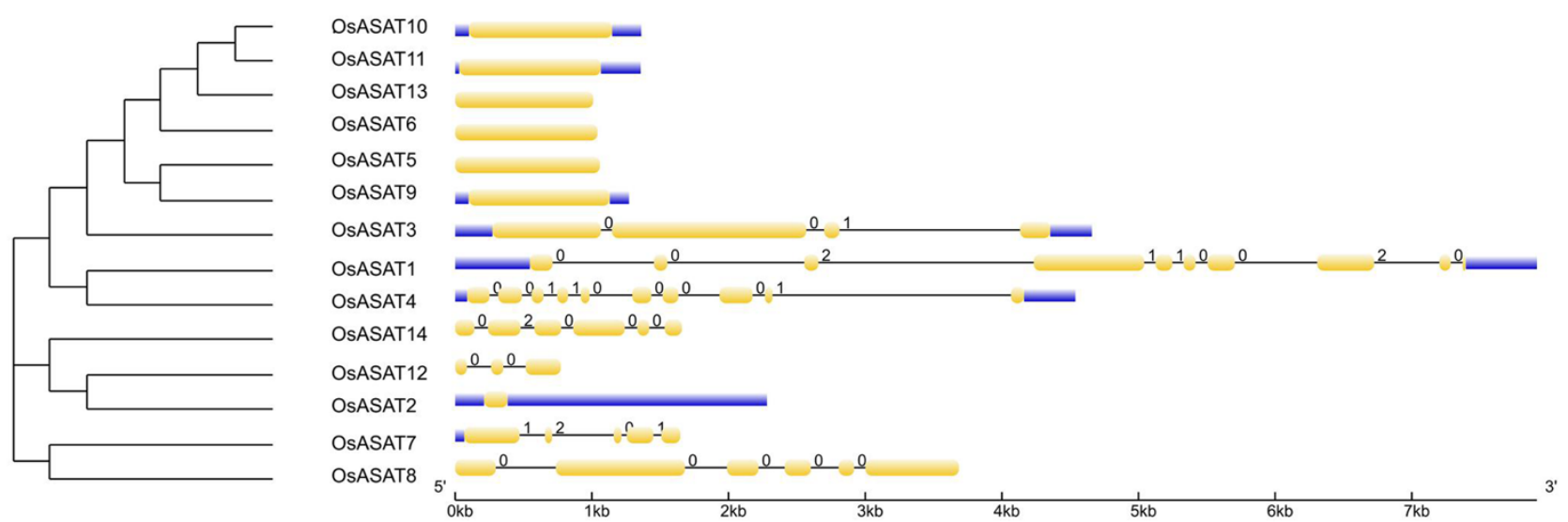

Legend:

CDS upstream/ downstream — Intron 012 intron phase

Figure 3 Analysis of gene structure of OSASAT genes

Note: The yellow and blue bars represent the CDS and the un-translated region (UTR), respectively, while the black line represents the intron. Numbers $(0,1,2)$ stand for the intron phases

Table 3 Basic physiological and chemical features of rice ASAT proteins

\begin{tabular}{|c|c|c|c|c|c|c|c|c|c|}
\hline $\begin{array}{l}\text { Protein } \\
\text { name }\end{array}$ & $\begin{array}{l}\text { Number } \\
\text { of amino } \\
\text { acids (aa) }\end{array}$ & $\begin{array}{l}\text { Molecular } \\
\text { weight } \\
(\mathrm{kD})\end{array}$ & $\mathrm{pI}$ & $\begin{array}{l}\text { Number of } \\
\text { negatively } \\
\text { charged residues } \\
\text { (Asp+Glu) }\end{array}$ & $\begin{array}{l}\text { Number of } \\
\text { positively } \\
\text { charged residues } \\
\text { (Arg+Lys) }\end{array}$ & $\begin{array}{l}\text { Total } \\
\text { number } \\
\text { of atoms }\end{array}$ & $\begin{array}{l}\text { Instability } \\
\text { index }\end{array}$ & $\begin{array}{l}\text { Aliphatic } \\
\text { index }\end{array}$ & $\begin{array}{l}\text { Hydrophobic } \\
\text { index }\end{array}$ \\
\hline OsASAT1 & 348 & 38.76 & 10.2 & 16 & 32 & 5558 & 57.65 & 113.02 & 0.615 \\
\hline OsASAT2 & 346 & 36.77 & 9.84 & 18 & 30 & 5245 & 44.48 & 103.41 & 0.605 \\
\hline OsASAT3 & 347 & 36.76 & 9.98 & 17 & 31 & 5241 & 47.41 & 100.86 & 0.557 \\
\hline OsASAT4 & 264 & 28.70 & 10.92 & 9 & 29 & 4109 & 43.15 & 103.56 & 0.438 \\
\hline OsASAT5 & 352 & 38.52 & 9.97 & 16 & 29 & 5477 & 40.82 & 102.36 & 0.559 \\
\hline OsASAT6 & 381 & 40.61 & 9.48 & 22 & 32 & 5772 & 44.19 & 100.58 & 0.553 \\
\hline OsASAT7 & 344 & 37.30 & 9.69 & 21 & 34 & 5341 & 52.69 & 110.76 & 0.622 \\
\hline OsASAT8 & 348 & 37.22 & 10.76 & 19 & 33 & 5344 & 44.96 & 112.82 & 0.599 \\
\hline OsASAT9 & 403 & 43.95 & 9.66 & 27 & 43 & 6257 & 53.93 & 101.09 & 0.424 \\
\hline OsASAT10 & 349 & 37.35 & 10.76 & 19 & 33 & 5361 & 44.77 & 112.49 & 0.603 \\
\hline OsASAT11 & 345 & 37.06 & 10.01 & 19 & 30 & 5299 & 36.79 & 108.46 & 0.63 \\
\hline OsASAT12 & 336 & 36.35 & 9.93 & 21 & 35 & 5188 & 53.38 & 102.74 & 0.556 \\
\hline OsASAT13 & 354 & 37.98 & 9.93 & 22 & 36 & 5420 & 52.61 & 103.36 & 0.590 \\
\hline OsASAT14 & 356 & 39.68 & 10.14 & 17 & 33 & 5687 & 55.91 & 111.57 & 0.578 \\
\hline
\end{tabular}

\subsection{Sequence alignment and functional domain analysis of rice ASAT family proteins}

In order to further clarify the structure and properties of rice ASAT family proteins, we carried out structural alignment and functional domain prediction of rice ASAT family proteins (Figure 4). The results showed that there were 12 conserved motifs with high similarity in the OsASAT protein sequence (Figure 4A), among which 7 motifs were completely consistent with Arabidopsis AtASAT1. It is worth noting that the distribution of conserved motif 1 9 of OsASAT family proteins is basically the same, showing the characteristics of high conservation. Subsequent online SMART detection of conserved motifs showed that motif 1 is a MBOAT superfamily domain, which usually ends with G (glycine) at the C-terminal of the protein (Figure 4B).

\subsection{Analysis of cis-acting elements of rice $\boldsymbol{A S A T}$ gene}

In terms of gene function, promoter is an important cis-acting element of gene expression, which determines the timing, location and quantitative expression of specific genes. In order to further study the evolution rate and characteristics of rice OsASAT gene family, we analyzed the cis-acting elements of OsASAT gene (Figure 5). The prediction results of cis-acting elements on the $2000 \mathrm{bp}$ sequence up-stream of the transcriptional initiation site of OsASAT gene showed that there was a total of 1756 cis-acting elements in the promoter of OsASAT gene family, 
Rice Genomics and Genetics 2021, Vol.12, No.1, 1-16

but the number of cis-acting elements varied greatly among gene individuals. Compared with other OsASAT, OSAST2 contained the least cis-acting elements. The largest proportion of cis-acting elements in all detected promoters were transcriptional core promoters such as CAAT-box (18.2\%) and TATA-box (16.4\%), followed by pressure response elements MYC (3\%) and MYB (2.1\%), and light response elements G-box (1.6\%), plant hormone response elements ABRE (1.2\%) and CGTCA-motif (1.1\%), and so on. The above results showed that the expression of OSASAT gene is regulated by a variety of internal and external signals, which may be involved in response to stress and play an important role in normal plant growth and development and hormone balance in vivo.

Table 4 Protein structures, subcellular localization and phosphorylation sites a of rice ASAT

\begin{tabular}{|c|c|c|c|c|c|c|c|c|c|c|}
\hline $\begin{array}{l}\text { Protein } \\
\text { name }\end{array}$ & $\begin{array}{l}\text { Alpha- } \\
\text { helix }(\%)\end{array}$ & $\begin{array}{l}\text { Beta turn } \\
(\%)\end{array}$ & $\begin{array}{l}\text { Extended } \\
\text { strand }(\%) \\
\end{array}$ & $\begin{array}{l}\text { Random } \\
\text { coil (\%) }\end{array}$ & $\begin{array}{l}\text { Numberof } \\
\text { predicted TMHs }\end{array}$ & $\begin{array}{l}\text { Subcellular } \\
\text { localization }\end{array}$ & Threonine & SEsrine & Tyrosine & $\begin{array}{l}\text { Total } \\
\text { sites } \\
\end{array}$ \\
\hline OsASAT1 & 53.16 & 4.31 & 14.08 & 28.45 & 6 & Chlo, Plas & 4 & 14 & 2 & 20 \\
\hline OsASAT2 & 57.8 & 3.18 & 9.54 & 29.48 & 7 & Chlo, Mito & 4 & 9 & 2 & 15 \\
\hline OsASAT3 & 51.87 & 3.75 & 11.82 & 32.56 & 5 & Chlo, Mito & 4 & 10 & 1 & 15 \\
\hline OsASAT4 & 54.55 & 4.17 & 8.33 & 32.95 & 5 & Chlo, Vacu., Plas & 2 & 18 & 0 & 20 \\
\hline OsASAT5 & 52.84 & 4.26 & 14.2 & 28.69 & 8 & Chlo, Vacu, Plas & 3 & 15 & 1 & 19 \\
\hline OsASAT6 & 51.18 & 2.62 & 11.02 & 35.17 & 7 & Cyto, Vacu, Plas, Pero & 5 & 11 & 3 & 19 \\
\hline OsASAT7 & 54.65 & 2.62 & 13.08 & 29.65 & 5 & Chlo, Plas, Vacu, E.R. & 4 & 15 & 2 & 21 \\
\hline OsASAT8 & 52.3 & 6.32 & 11.49 & 29.89 & 7 & Chlo, Mito & 5 & 12 & 1 & 18 \\
\hline OsASAT9 & 51.61 & 3.47 & 10.17 & 34.74 & 5 & Plas, Chlo, Vacu, Nucl & 6 & 18 & 3 & 27 \\
\hline OsASAT10 & 49.86 & 6.3 & 11.17 & 32.66 & 7 & Chlo, Mito & 9 & 16 & 2 & 27 \\
\hline OsASAT11 & 56.23 & 5.51 & 11.3 & 26.96 & 8 & Chlo, Mito & 4 & 9 & 1 & 14 \\
\hline OsASAT12 & 52.68 & 6.25 & 11.61 & 29.46 & 6 & Chlo, Plas, Mito, E.R. & 9 & 15 & 2 & 26 \\
\hline OsASAT13 & 53.39 & 4.8 & 9.89 & 31.92 & 7 & Chlo, Plas & 9 & 16 & 2 & 27 \\
\hline OsASAT14 & 51.97 & 3.65 & 14.33 & 30.06 & 7 & Plas, Vacu, E.R. & 5 & 14 & 2 & 21 \\
\hline
\end{tabular}

A

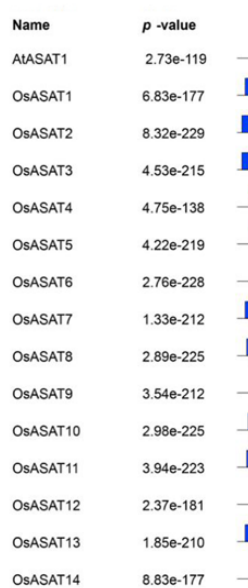

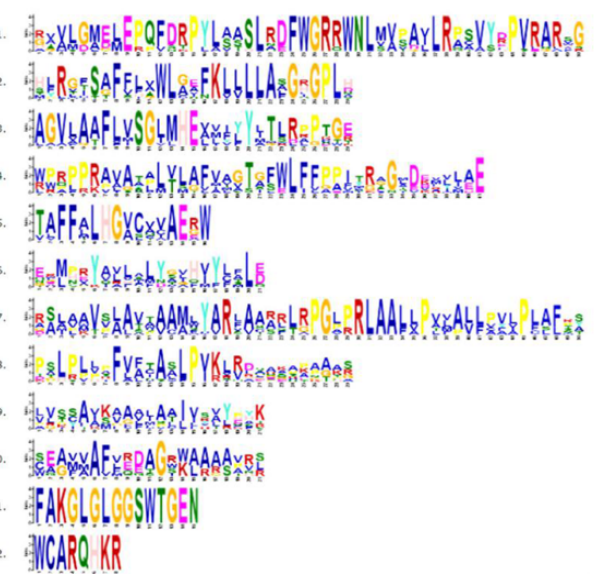

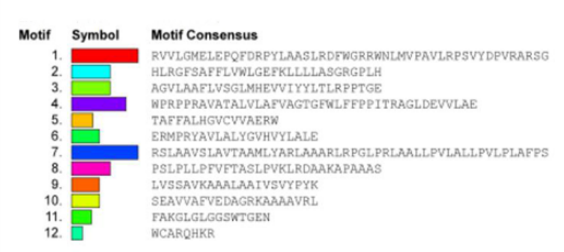

Figure 4 Alignment of Arabidopsis AtASAT1 with rice ASATs and prediction of conserved motif patterns among them Note: A: The distribution and sequence of motifs; B: Highly conserved motif patterns of ASAT family 
Rice Genomics and Genetics 2021, Vol.12, No.1, 1-16
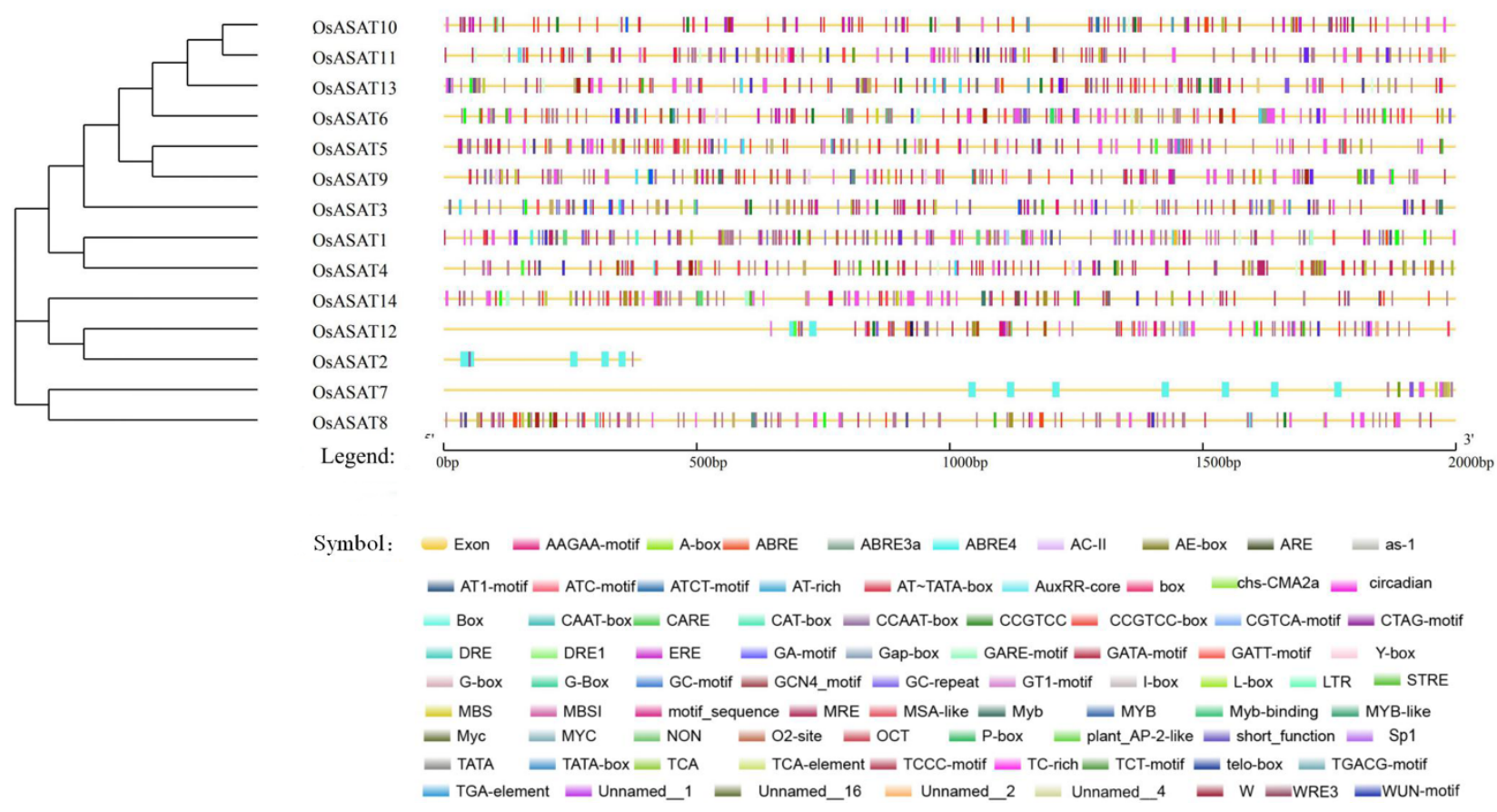

Figure 5 Cis-acting element structures in promoter regions of rice $A S A T$ family members

\subsection{Cluster analysis of expression patterns of rice $A S A T$ gene family}

Analyzing the expression characteristics of OSASAT gene in biotic stress and abiotic stress, different developmental stages and tissue space can provide a basis for further analysis of the function of OsASAT protein. Firstly, we used the genevestigator (https://genevestigator.com/) to draw the spatial expression heat map of rice OsASAT in 36 different rice tissues (Figure 6). And it is obvious that OSASAT gene has obvious tissue expression specificity. Among them, OSASAT10 is only expressed in a few vegetative tissues, while OSASAT14 is expressed to varying degrees in more vegetative organs, especially in Internode tissues and young roots. However, the expression of these two genes in reproductive organs is so weak that it seems impossible to participate in the development of reproductive organs. OSASAT4 and OSASAT9 were specifically up-regulated in bud and flower (stamen, anther, pollen, pistil), which may play a major role in the development of rice reproductive organs. In addition, the highest expression levels of them were found in the seedling and coleoptile, suggesting that they may be involved in seed germination and seedling establishment. OSASAT6 was highly expressed in roots and reached the highest level in internodes. It is worth noting that all OSASAT genes are expressed in caryopsis or rice panicles, which supports our speculation that OSASAT may be involved in steryl ferulate synthesis (Figure 6A).

The results of the line chart of OSASAT expression at 9 different developmental stages (Figure 6B) showed that the dynamic expression profiles of each OSASAT gene had their own characteristics. Among them, OsASAT4 showed a sustained and stable high-level expression, and the expression level was significantly higher than that of other OSASAT genes. Except for OSASAT1, the expression of other OSASAT genes was up-regulated at the fruiting stage (flowering stage, milk stage and dough stage), suggesting that they may be involved in the process of seed development. Expression patterns of rice $A S A T$ genes in 48 tissues at different developmental stages (Figure 6C) showed that no significant gene expression changes were found in the diurnal tissues except OsASAT10 and OSASAT14 in the leaf sheath, indicating that the expression patterns of each gene were stable during the diurnal variation. In addition, the spatiotemporal expression of most $O S A S A T$ genes has a broad spectrum, but several OSASAT genes have opposite expressions during specific organ development, such as OsASAT5 and OsASAT14 
(anther development), OSASAT11 and OSASAT14 (pistil development), OsASAT5 and OSASAT9 (embryo development), and OSASAT10 and OSASAT9 (endosperm development).

These results reflect the possible functional redundancy among these OSASAT genes from one aspect. We noticed that during embryo development, the expression of OSASAT5 was high and stable, while the expression of OsASAT3 and OsASAT10 was steadily up-regulated, and the expression of OsASAT4, OsASAT11 and OsASAT14 was up-regulated at first and then down-regulated, suggesting that they may be involved in the regulation of embryo development. In the process of endosperm development, OsASAT10 has ultra-high expression while OsASAT9 shows ultra-low down-regulation, the expression of OSASAT5 continues to up-regulate, and the expression of OSASAT14 is down-regulated at first and then up-regulated, suggesting that they play different roles in different processes of endosperm development. And it must be pointed out that the genevitagator platform lacks the data of OsASAT2, OsASAT7, OsASAT8, and OsASAT12.

Then, we collected the mRNA expression data of ASAT protein coding genes in roots and seedlings under different hormone treatments from RiceXPro and carried out gene expression pattern cluster analysis (Figure 7). The results showed that each gene showed tissue expression specificity in hormone response. In root tissue (Figure 7A), gibberellin, auxin and brassinosteroid promoted most of OSASAT gene expression up-regulation, while jasmonic acid inhibited most gene expression. And gene expression showed significant differences with treatment of cytokinin and abscisic acid, and the expression of single gene changed significantly with hormone concentration, in which OSASAT11 expression was very sensitive to abscisic acid. In the seedlings (Figure 7B), the gene expression changed greatly caused by each hormone treatment. Interestingly, cytokinin and gibberellin inhibited OSASAT11 expression, while abscisic acid and jasmonic acid promoted OSASAT11 expression. Jasmonic acid significantly inhibited the expression of OSASAT5 and OSASAT10, while abscisic acid and gibberellin inhibited and promoted the expression of OSASAT14, respectively. Unlike other OSASAT, the OsASATI expression is less affected by hormones. These results indicated that the response of members of OSASAT gene family to hormones is specific at both tissue and hormone levels, which is not exactly the same, reflecting the diversity of their biological functions. It should be noted that the RiceXPro platform lacks the data of OSASAT2, OsASAT6, OsASAT7, OsASAT8, OsASAT12, and OsASAT13.

Because sterol esters are reported to be involved in plant stress response, which is related to drought stress and membrane lipid metabolism (Kumar et al., 2018), we also obtained RNA-SEsq data (GSEs74793) of Azuenca rice ASAT protein family coding genes from AIPuFu (www.aipufu.com) under drought and heat for different times and analyzed their expression changes under abiotic stress such as drought and heat (Figure 8). As shown by heat map and hierarchical cluster analysis, OSASAT gene family was differentially expressed in different periods of drought and heat. Heat or drought promoted the high expression of OSASAT3 and OsASAT4, while inhibited the expression of other OSASAT genes. These results showed that OSASAT gene may have functional division and coordinated control under abiotic stress, while OSASAT3 and OSASAT4 genes may play a role in abiotic stress of drought and heat in rice. 
Rice Genomics and Genetics 2021, Vol.12, No.1, 1-16

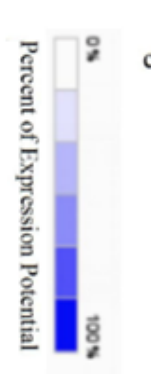

$$
\begin{array}{r}
\text { callus } \\
\text { cell culture/primary cell } \\
\text { seedling } \\
\text { coleoptile } \\
\text { leaf } \\
\text { root } \\
\text { radicle } \\
\text { inflorescence } \\
\text { panicle } \\
\text { spikelet } \\
\text { floret } \\
\text { stamen } \\
\text { anther } \\
\text { pollen } \\
\text { pistil } \\
\text { stigma } \\
\text { ovary } \\
\text { panicle branch } \\
\text { caryopsis } \\
\text { shoot } \\
\text { culm (stem) } \\
\text { node } \\
\text { internode } \\
\text { stele } \\
\text { pith } \\
\text { parenchyma } \\
\text { peduncle } \\
\text { leaf } \\
\text { flag leaf } \\
\text { crown } \\
\text { shoot apex } \\
\text { rhizome } \\
\text { roots } \\
\text { primary root } \\
\text { primary root tip } \\
\text { unspecified roo type } \\
\text { unspecified root tip }
\end{array}
$$
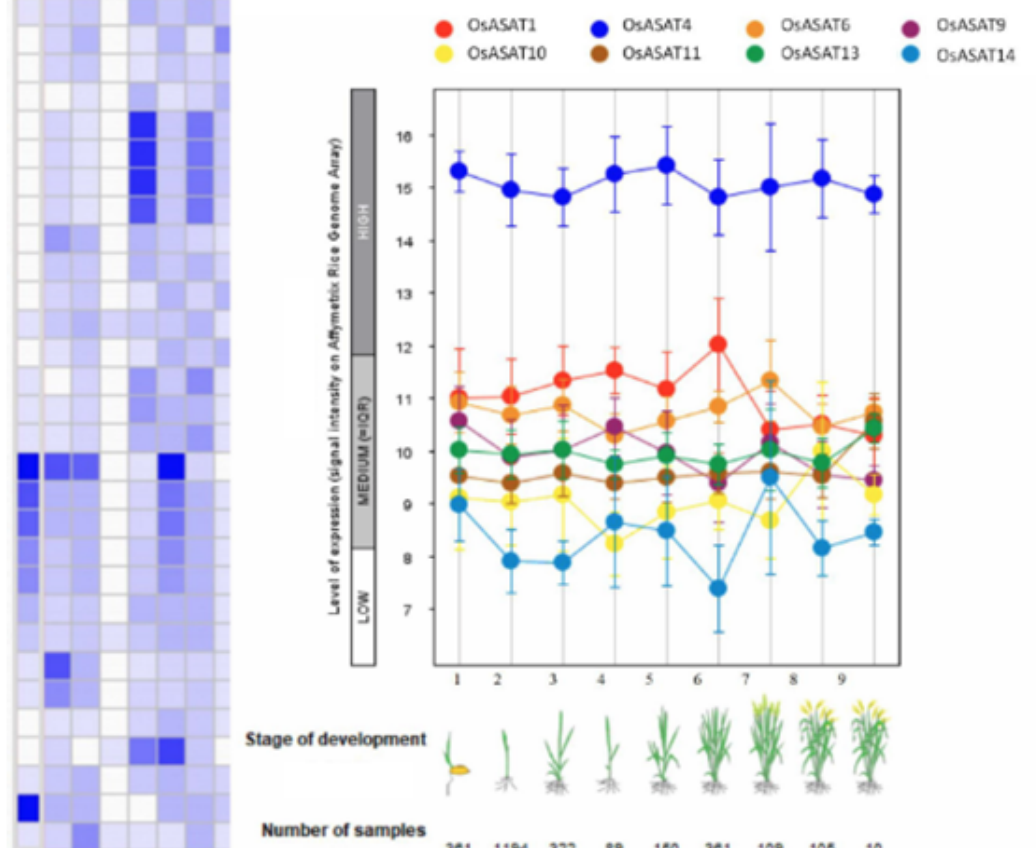

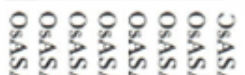

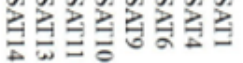
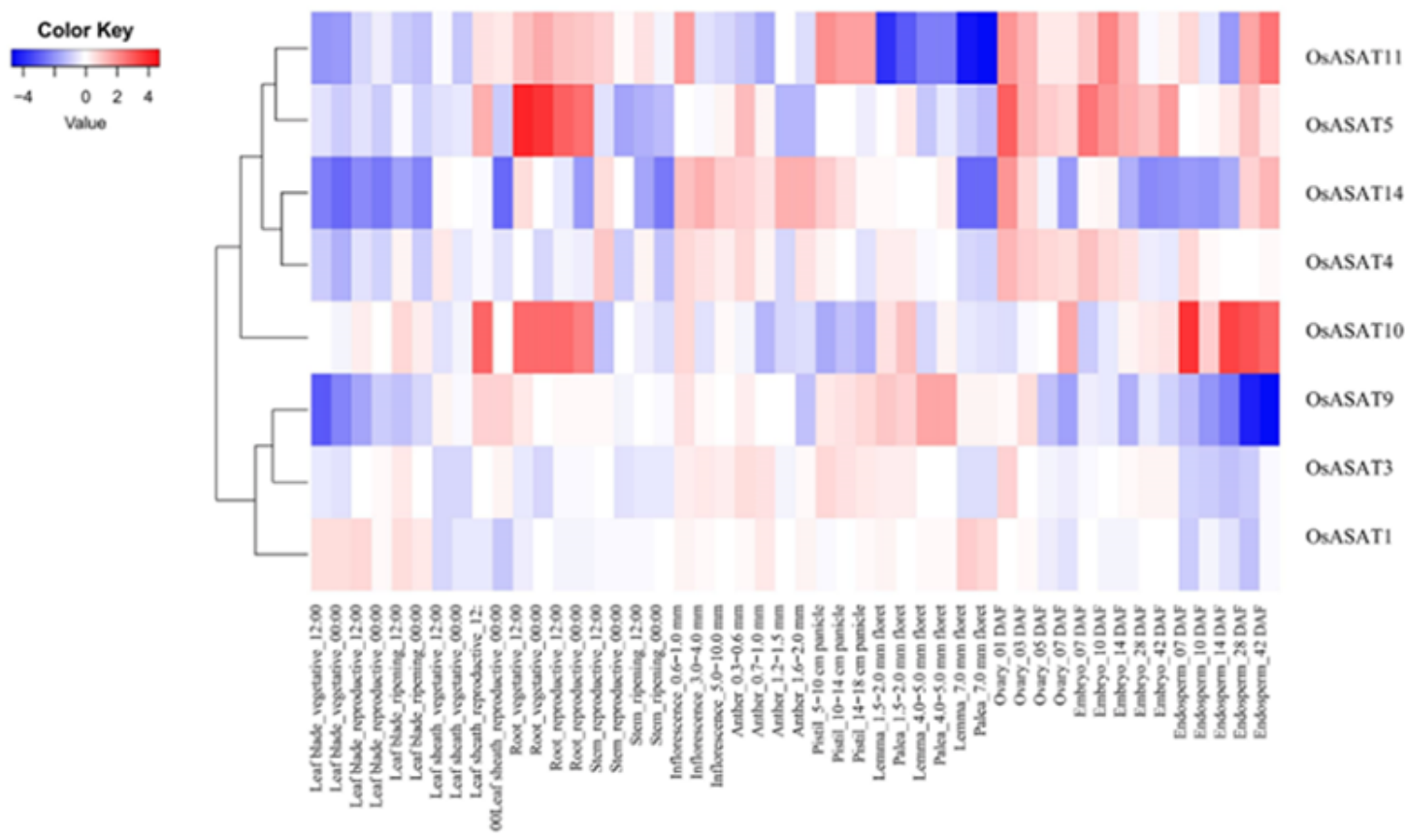

tissue and developmental time

Figure 6 Spatio-temporal expression patterns of OsASAT genes

Note: A: Expression patterns of rice ASAT genes in 36 different tissues; 1: Germination; 2: Seedling; 3: Tillering stage; 4: Stem elongation stage; 5: Booting stage; 6: Heading stage; 7: flowering stage; 8: Milk stage; 9: Dough stage; B: Line charts of the kinetic expression patterns of rice $A S A T$ genes along rice plant development; C: Expression patterns of rice $A S A T$ genes in 12 tissues at different developmental stages 
A

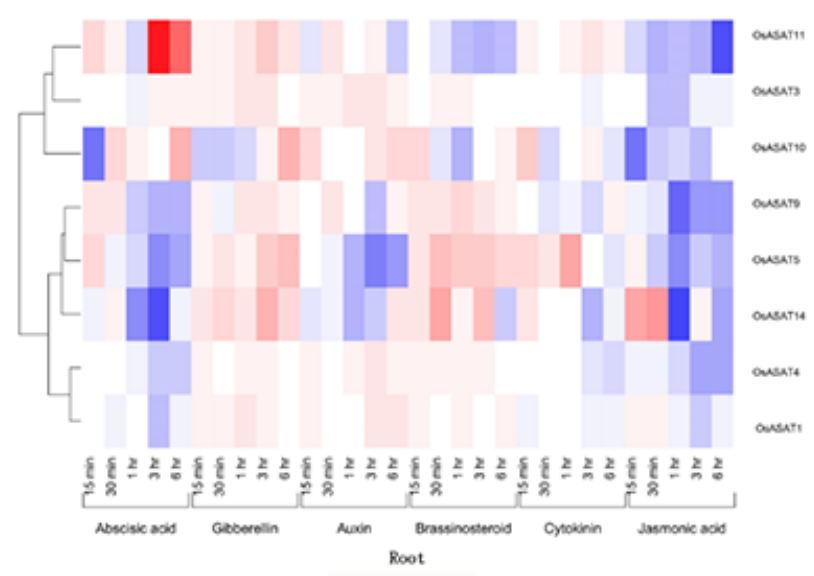

B

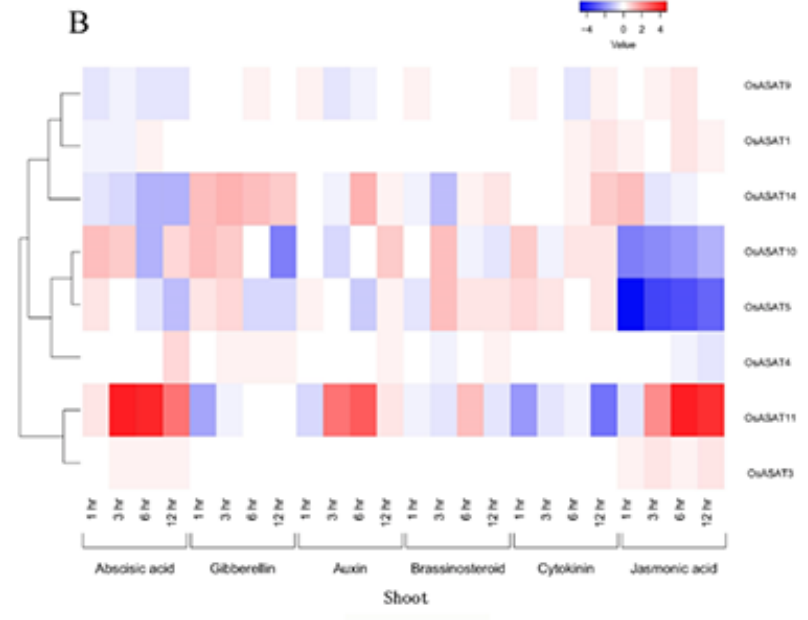

Figure 7 Cluster analysis of expression patterns of $A S A T$ genes responding to hormone treatments in rice Note: A: Underground root; B: Above-ground seedlings

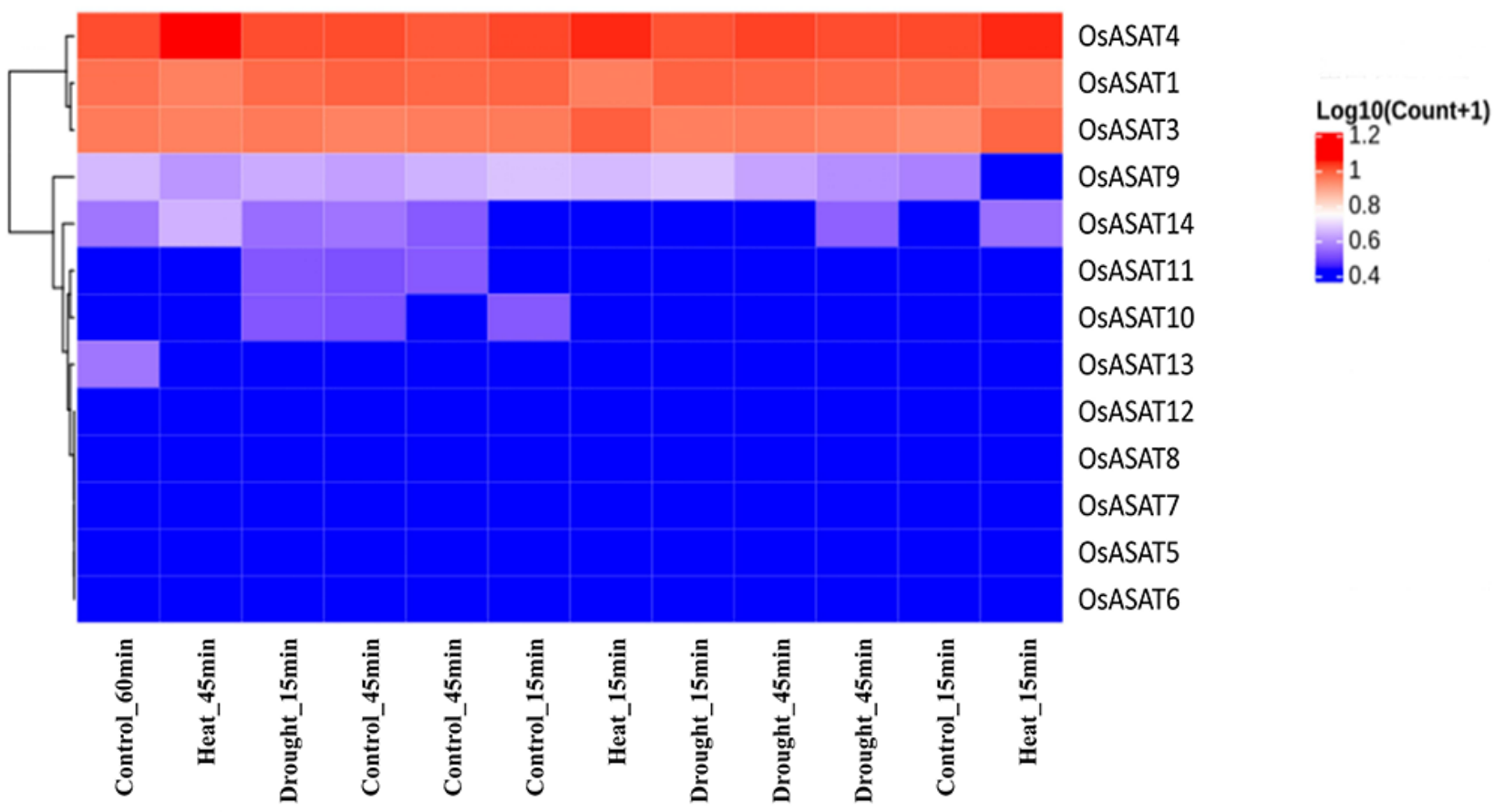

Figure 8 Cluster analysis of expression patterns of OSASAT genes responding to abiotic stress

\section{Discussion}

Plant is famous for large and diverse chemical metabolites. Steryl ferulate, as an important secondary metabolite in plants, plays an important role in maintaining membrane lipid homeostasis, regulating membrane permeability, fluidity, signal transduction and membrane binding enzyme activity. For rice, steryl ferulate is an important component of rice bran oil. It is an important topic in rice bran oil metabolic biology to study the protease function and heredity and evolution of steryl ferulate metabolism pathway. Based on the chemical structure of steryl ferulate, it is inferred that OsASAT enzyme may be involved in the synthesis of steryl ferulate. So far, only ASAT enzymes from Arabidopsis and tomato have been cloned and identified, which are involved in sterol ester synthesis and sterol metabolism. The function of ASAT in other plants has not been reported. In addition, the synthesis and metabolic pathway of phytosteryl ferulate have not been revealed. The study on the evolutionary characteristics, expression patterns and biological functions of ASAT family molecules in different species is helpful not only to the cloning and functional identification of $A S A T$ genes in other species, but also to the 
understanding of rice bran oil biosynthesis pathway. In this study, we identified 96 ASAT family members from public genome database of 8 plant species including Arabidopsis and tomato, and focused on the bioinformatics analysis of 14 rice ASAT (OsASAT) proteins.

We constructed phylogenetic tree of 105 ASAT protein family members including Arabidopsis thaliana and tomato. The results showed that the origin and evolution of Arabidopsis AtASAT1 was more similar to peanut, rape and rice. The number of OsASAT protein is more than that of SIASAT, and both of them are scattered in the evolutionary tree. However, the genetic distance between tomato SIASAT1 and Arabidopsis AtASAT1 is farther, and the genetic distance between OsASAT2, OsASAT3, OsASAT4, OsASAT5, OsASAT6 and OsASAT9 in rice is closer to Arabidopsis AtASAT1. OsASAT1, OsASAT7 and OsASAT13, which are close to tomato SlASAT1. It is speculated that these proteins may have functions similar to sterol acyltransferases. On the other hand, there is good homology between OsASAT and ASAT proteins of maize and sorghum in food crops, and the time of evolution divergence is closer. The members of ASAT family identified in monocotyledons and dicotyledons showed good homology. Also, there are obvious clustering phenomena of ASAT proteins in typical oil crops and food crops, indicating that the ASAT protein family may play a certain role in the evolution or differentiation of oil crops and food crops. It should be noted that there is no one-to-one correspondence between the number and homology of plant ASAT protein family members, suggesting that ASAT is involved in the differentiation of different species and has experienced different evolutionary processes.

The OsASAT protein localization is diverse, and chloroplast and plasma membrane localization account for the largest proportion, which is similar to the results in Arabidopsis and tomato (Chen et al., 2007; Lara et al., 2018). At present, it has been confirmed that the biosynthesis of phytosterol and ferulic acid occurs in the cytoplasm (Suzuki and Muranaka, 2007; Li et al., 2008; Saulnier et al., 2012). But the enzyme system involved in the esterification of ferulic acid and sterol is not clear. And our analysis can provide a reference for the cellular localization of sterol ferulic acid esterification. We analyzed the synonymous and non synonymous sites of OsASAT coding genes, and concluded that OsASAT coding genes tended to purify selection. The appearance of ASAT gene cluster structure in different species suggests that the ASAT family coding genes may be replicated in the process of evolution, and then the new gene sequence and protein structure will be changed correspondingly through recombination and mutation, and finally show functional diversity. Gene clustering has a selective advantage in evolution, and it has been proved that gene clustering plays an important role in rice seed dormancy and resistance (Ye et al., 2020). The evolutionary characteristics of the clustering of ASAT coding genes in rice may be related to their specialized biological functions.

The molecular weight and secondary structure of OsASAT and AtASAT1 proteins are similar, indicating that the ASAT family members are conserved in evolution, which is consistent with the above results of synonymous and non synonymous sites analysis. The analysis of transmembrane helix structure showed that OsASAT protein was probably located in the membrane related structure. On the one hand, it complemented the results of subcellular localization. On the other hand, it might correspond to the characteristics of OsASAT protein, such as alkaline, high fat solubility and high instability index. It should be noted that 7 motifs of OsASAT protein sequence are identical to Arabidopsis AtASAT1, and motif 1 is a MBOAT superfamily domain. MBOAT family members include several key enzymes in lipid metabolism and protein acyltransferases involved in signal transduction, such as ASAT acyl-CoA: DGAT, LAT, and GOAT. These results provide a valuable molecular reference for the study of the function of OsASAT protein involved in lipid metabolism, especially in rice bran oil metabolism.

The structure of OSASAT genes varies greatly among individuals, but the genes with close evolutionary distance have similar structure and expression patterns, such as OSASAT1 and OSASAT4. Consistent with the reports of other species (Chen et al., 2007; Lara et al., 2018), different OSASAT genes have different expression specificity in tissues and developmental stages, which proves that OSASAT, like ASAT genes in Arabidopsis and tomato, not only participates in the esterification of phytosterols and acids, maintains sterol homeostasis, but also affects the growth and development of plant nutrition and reproductive organs. On the other hand, the cis-acting element 
found in the promoter region of the OSASAT gene family indicates that OSASAT plays an important role in both biotic and abiotic stress responses in rice, which is similar to the reported result that SIASAT has dual response to plant stress.

Based on all analysis data, especially the spatiotemporal expression data, and compared with Arabidopsis AtASAT1 and tomato ASAT, we speculated that OsASAT4, OsASAT5, OsASAT9, OsASAT10, OsASAT11 and OsASAT14 are most likely to be involved in the synthesis of rice bran oil. Study on the follow-up function of single enzyme evolution will provide a solid theoretical basis for further study of the analysis of rice bran oil metabolic pathway.

\section{Materials and Methods}

\subsection{Data download and identification of Plant ASAT family members}

AtASAT gene information was downloaded from the Arabidopsis information resource (TAIR, http://www.arabidopsis.org/), rice gene and protein sequence were downloaded from RiceData (http://rice.plantbiology.msu.edu/). The proteome sequences, genome sequences and gene annotation files of the other 8 species were derived from National center of biotechnology information (NCBI, https://ftp.ncbi.nlm.nih.gov/genomes/). Using Arabidopsis AtASAT1 protein sequence as query, ASAT homologous proteins $\left(E-v a l u e=1 \mathrm{e}^{-10}\right.$ ) of other species were searched by Blast 2.5.0 software. After the primary ASAT family members were obtained, the redundant sequences were removed by tblastn. At the same time, the preliminary functional domains of the initial protein sequences were detected and analyzed by CDD website (http://www.ncbi.nlm.nih.gov/Structure/bwrpsb/bwrpsb.cgi) and SMART website (http://smart.embl-heidelberg.de/), and finally the candidate members of ASAT family were screened. The ASAT homologous protein named as "the abbreviation of the first letter of the Latin name of the species+ASAT+number" according to its position on the chromosome.

\subsection{Analysis of rice ASAT family proteins}

The molecular weight and theoretical isoelectric point of the protein were predicted by ComputepI/MW on the online website ExPASy (https://web.expasy.org/compute_pi/). The first-order physical and chemical properties (such as the number of charged residues, total atoms, instability index, aliphatic index, and Hydrophobic index) were predicted by online software ProtParam (https://web.expasy.org/protparam/). The prediction of protein secondary structure was completed by SOPMA online tool (https://npsaprabi.ibcp.fr/cgibin/npsa_automat.pl?page=npsa_sopma.html). Transmembrane structure was finished by TMHMM website (http://www.cbs.dtu.dk/services/TMHMM/). Protein signal peptides were detected by SignalP-5.0 (http://www.cbs.dtu.dk/services/SignalP/). Phosphorylation sites were detected by NetPhos3.1 Server (www.cbs.dtu.dk/services/NetPhos/). Protein subcellular localization was completed by the integration of TargetP (http://www.cbs.dtu.dk/services/TargetP/), ChloroP (http://www.cbs.dtu.dk/services/ChloroP/) and WoLF PSORT prediction results. The amino acid sequence alignment of ASAT protein domain was completed by MEME (http://meme-suite.org/) online software Cluster W2.

\subsection{Chromosome location, gene structure and promoter analysis of rice $A S A T$ gene}

The chromosome location of OSASAT gene was mapped by TBtools software. The structure of OSASAT gene was analyzed by online software GSDS (http://gsds.cbi.pku.edu.cn/). Gene synonymous sites were analyzed by software DnaSP (http://www.ub.edu/dnasp/). The analysis of cis-acting elements of promoter was completed by online software PlantCARE (http://bioinformatics.psb.ugent.be/webtools/plantcare/html/).

\subsection{Construction of phylogenetic tree of ASAT protein family}

MEGA-X software (Kumar et al., 2018) was used to construct the phylogenetic tree of ASAT family proteins of 9 species. ClustalW2 was used to carry out multiple sequence alignment of protein sequence, with parameter of Gap Opening Penalty=10, Gap Extension Penalty=0.2, Delay Divergent Cutoff $=30 \%$. Then the maximum likelihood method was used to construct the phylogenetic tree, and with the parameter of Bootstrap $=1000$. 
Rice Genomics and Genetics 2021, Vol.12, No.1, 1-16

\subsection{Gene expression and cluster analysis of rice ASAT family}

We obtained the gene expression information of rice $A S A T$ gene in hormone treatment, abiotic stress, different developmental stages and different tissues (including embryo and endosperm) through RiceXPro (http://ricexpro.dna.affrc.go.jp/category-SEslect.php), rice expression database AIPuFu (www.aipufu.com), and genevestigator platform (https://genevestigator.com/). And we derived expression map through platform.

\section{Authors' contributions}

SWL was the designer and executor of this study, completed the data analysis, drafted the manuscript, and participated in the experiment design and analysis. SJX conceived and directed of the study, guided experiment design, data analysis, and draft and revision of the manuscript. Both authors read and approved the final manuscript.

\section{Acknowledgments}

This study was supported by National Natural Science Foundation of China (31971907) and Plan of Innovative Intelligence Introduction in College and University (program 111, B14016).

\section{Reference}

Banas A., Carlsson A. S., Huang B., Lenman M., Banas W., and Lee M., 2005, Cellular sterol ester synthesis in plants is performed by an enzyme (phospholipid:sterol acyltransferase) different from the yeast and mammalian acyl-CoA:sterol acyltransferases, J. Biol. Chem., 280(41): 34626-34634 https://doi.org/10.1074/jbc.M504459200

Bouvier-Nave P., Berna A., Noiriel A., Compagnon V., Carlsson A. S., Banas A., Stymne S., and Schaller H., 2010, Involvement of the phospholipid sterol acyltransferasel in plant sterol homeostasis and leaf senescence, Plant Physiol., 152(1): 107-119 https://doi.org/10.1104/pp.109.145672

Bumrungpert A., Chongsuwat R., Phosat C., and Butacnum A., 2019, Rice bran oil containing gamma-oryzanol improves lipid profiles and antioxidant status in hyperlipidemic subjects: a randomized double-blind controlled trial, J. Altern. Complem. Med., 25(3): 353-358 https://doi.org/10.1089/acm.2018.0212

Faulds C.B., 2010, What can feruloyl esterases do for us ? Phytochem Rev., 9(1): 121-132 https://doi.org/10.1007/s11101-009-9156-2

Gasteiger E., Hoogland C., Gattiker A., Duvaud S., Wilkins M.R., Appel R.D., and Bairoch A., 2005, Protein identification and analysis tools on the ExPASy server, In: Walker J.M., (ed), The Proteomics Protocols Handbook, Humana Press Inc., Totowa, USA, pp.571-607 https://doi.org/10.1385/1-59259-890-0:571

Harker M., Hellyer A., Clayton J.C., Duvoix A., Lanot A., and Safford L.R., 2003, Co-ordinate regulation of sterol biosynthesis enzyme activity during accumulation of sterols in developing rape and tobacco seed, Planta, 216(4): 707-715 https://doi.org/10.1007/s00425-002-0913-3

Hernandez E.M., 2016, Specialty oils: functional and nutraceutical properties, In: Sanders T.A.B., (ed), Functional Dietary Lipids, Food Formulation, Consumer Issues and Innovation for Health, Woodhead Publishing, USA, pp.69-101 https://doi.org/10.1016/B978-1-78242-247-1.00004-1

Kumar M.S.S., Mawlong I., Ali K., and Tyagi A., 2018, Regulation of phytosterol biosynthetic pathway during drought stress in rice, Plant Physiol Bioch., 129: $11-20$ https://doi.org/10.1016/i.plaphy.2018.05.019

Kumar M.S.S., Ali K., Dahuja A., and Tyagi A., 2015, Role of phytosterols in drought stress tolerance in rice, Plant Physiol. Bioch., 96: 83-89 https://doi.org/10.1016/i.plaphy.2015.07.014

Kumar S., Stecher G., Li M., Knyaz C., and Tamura K., 2018, MEGA X: molecular evolutionary genetics analysis across computing platforms, Mol. Biol. Evol., 35(6): 1547-1549 https://doi.org/10.1093/molbev/msy096

Lai O.M., Jacoby J.J., Leong W.F., and Lai W.T., 2019, Nutritional studies of rice bran oil, In: Cheong L.Z., and Xu X., (eds.), Rice Bran and Rice Bran Oil, Chemistry, Processing and Utilization, Academic Press and AOCS Press, USA, pp.19-54 https://doi.org/10.1016/B978-0-12-812828-2.00002-0

Lara J.A., Burciaga-Monge A., Chávez A., Revés M., Lavilla R., Arró M., Boronat A., Altabella T., and Ferrer, 2018, Identification and characterization of sterol acyltransferases responsible for steryl ester biosynthesis in tomato, Front Plant Sci, 9: 588 https://doi.org/10.3389/fpls.2018.00588

Li L., Shewry P.R., and Ward J.L., 2008, Phenolic acids in wheat varieties in the HEALTHGRAIN diversity screen, J. Agr. Food Chem., 56(21): 9732-9739 https://doi.org/10.1021/jf801069s

Chen Q., Steinhauer L., Hammerlindl J., Keller W., and Zou J., 2007, Biosynthesis of phytosterol esters: identification of a sterol o-acyltransferase in Arabidopsis, J. Plant Physiol., 145(3): 974-984 https://doi.org/10.1104/pp.107.106278 
Rice Genomics and Genetics 2021, Vol.12, No.1, 1-16

Saji N., Francis N., Schwarz L.J., Blanchard C.L., and Santhakumar A.B., 2019, Rice bran derived bioactive compounds modulate risk factors of cardiovascular disease and type 2 diabetes mellitus: an updated review, Nutrients, 11(11): 2736 https://doi.org/10.3390/nu11112736

Saulnier L., Guillon F., and Chateigner-Boutin A.L., 2012, Cell wall deposition and metabolism in wheat grain, J. Cereal. Sci., 56(1): 91-108 https://doi.org/10.1016/j.jcs.2012.02.010

Suzuki M., and Muranaka T., 2007, Molecular genetics of plant sterol backbone synthesis, Lipids, 42(1): 47-54 https://doi.org/10.1007/s11745-006-1000-5

Valitova J., Sulkarnayeva A., and Minibayeva F.V., 2016, Plant sterols: diversity, biosynthesis, and physiological functions, Biochemistry-Moscow, 81(8): $819-834$ https://doi.org/10.1134/S0006297916080046

Ye C.Y., Wu D., Mao L., Jia L., Qiu J., Lao S., Chen M., Jiang B., Tang W., Peng Q., Pan L., Wang L., Feng X., Guo L., Zhang C., Kellogg E. A., Olsen K.M., Bai L., and Fan L., 2020, The genomes of the allohexaploid echinochloa crus-galli and its progenitors provide insights into polyploidization-driven adaptation, Mol. Plant, 9(7): 1298-1310 https://doi.org/10.1016/j.molp.2020.07.001

Zhu D., 2015, Characterization of individual steryl ferulates: occurrence in rice, antioxidant and caco-2 cell permeation properties, Dissertation for Ph.D, Swiss Federal Institute of Technology in Zurich, Supervisor: Nyström L., pp. 3-20 